\title{
The Techno-Business/Academic Consortium: Defining The Key Information Skills Matrix
}

Donald J. Caputo (E-mail: caputo@rmu.edu), Robert Morris University

\begin{abstract}
This researcher surveyed a significant representation of the Southwestern Pennsylvania regional technological corporate community to determine what information skills, services, functions and business intelligence resources are needed to meet the rapidly changing workforce environment. Two associations in this area engage the academic community in developing the regional economy. The Pittsburgh Technology Council (PTC), and the Association of Information Technology Professionals (AITP), in partnership with four Pittsburgh higher education entities (Robert Morris University, Carnegie Mellon University, University of Pittsburgh, and Duquesne University), play a critical role in the formulation of this study. Specific skills of a technological nature, as well as general areas of computer-related competencies, such as networking and application development are derived and surveyed. Corporations are placed in categories by size, and nature of service (such as government, health care and not-for-profit entries). A matrix is constructed that displays the key technological skills considered most necessary (essential) to continued workforce advantage. Within that framework, an analysis of which skills, functions and services are most often outsourced and which are performed in-house, complete the survey.
\end{abstract}

\section{Introduction}

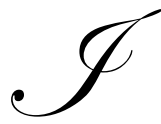

nformation Technology (IT) has rapidly become one of the largest and most important segments of the U.S. economy. In Southwestern Pennsylvania, the IT cluster contains more than 2,000 firms that employ more than 39,000 workers, and accounts for $15 \%$ of all the region's job growth over the past decade. Within the same time frame, a convergence toward technology has blurred the distinctions between "old line" manufacturing entities, service industries and state-of-the-art techno-business enterprises.

While IT is one of the key drivers for success in the global economy, it alone does not create business value. The synergy of corporate and academic partnerships permits coordinated development of a technology-related workforce through regional initiatives that are designed to meet employer-defined needs. The ensuing skills development process ensures that the emerging workforce is in sync with the technology-driven sector.

Universities and corporations are sometimes at opposite ends of a spectrum, with conflicting cultures and values. Technological consortiums act as a liaison that permits a "fusion" of priorities and goals in a sustainable partnership. As an example, the rapid changes in the occupational competencies needed in the job market will require a redefinition of necessary technological skills that must be woven into the fabric of corporate business management.

\section{Problem Definition And Method}

The challenge is to improve the linkages between industry and higher education in order to create a workforce system that is more customized, flexible and responsive to the needs of employers. How can we, as an academic institution, add more reliable, just-in-time services, technological skills, and business intelligence to the sector, much as businesses have had to do with their products? 
Two associations in the Southwestern area of Pennsylvania actively engage the academic community in developing the regional economy. The Pittsburgh Technology Council (PTC) and the Association of Information Technology Professionals (AITP), in partnership with four Pittsburgh Universities (Robert Morris University, Carnegie Mellon University, University of Pittsburgh, Duquesne University), in allegiance with nearly 1,800 Pittsburgh corporations share in the development of the region's economy.

This researcher surveyed a significant representation of the Southwestern Pennsylvania regional technological corporate community to determine what services, skills and business intelligence resources are needed to meet the rapidly changing workforce environment. Specific skills of a technological nature, as well as general areas of computer-related competencies, such as networks and databases, are derived. Corporations are placed in categories of size, service, government, health-care, and not-for-profit entries. A matrix is constructed that displays the technological skills considered most necessary to continued strategic workforce advantage. Within that framework, an analysis of which skills, functions and services are most often outsourced and which are performed in-house, complete the survey.

Tables I, II and III depict the I.T. skills that are integrated into the curriculum of the undergraduate Information Science and Information Systems Management courses at Robert Morris University. The percentage figures indicate the number of corporations that considered the named attribute as a specific key I.T. skill, an assessment that weighed heavily in employment decisions.

A large corporation is here defined as one with 500 or more employees. Many are multi-national, multidivision or multi-site in nature.

Table II depicts the same skill set and percentage figures for corporations that have less than 500 employees and are normally single-site and local in nature.

Table III depicts the same skill set and percentage figures for corporations that are health care-oriented, government-organized, or not-for-profit. Because many of these entities share two or all three characteristics of the category, it is difficult to place them in a single genre. For example, a large federal hospital system falls into all three categories. The number of workers employed in each of these corporations is not a factor in the table.

\begin{tabular}{|lr|}
\hline \multicolumn{2}{|c|}{ Table I. Key Information Specific Skills } \\
Large Corporate
\end{tabular}

\begin{tabular}{|lr|}
\hline \multicolumn{2}{|c|}{ Table II. Key Information Specific Skills } \\
Small Corporate \\
\hline HTML \\
XML & $65 \%$ \\
ASP & $9 \%$ \\
PERL & $30 \%$ \\
Front Page/Dreamweaver & $0 \%$ \\
Java & $21 \%$ \\
C++ & $42 \%$ \\
COBOL & $9 \%$ \\
Visual Basic & $3 \%$ \\
C\# & $42 \%$ \\
.NET & $24 \%$ \\
M & $27 \%$ \\
A+ & $0 \%$ \\
SQL & $12 \%$ \\
Oracle & $21 \%$ \\
Project Management & $30 \%$ \\
Programming Logic & $27 \%$ \\
Object-oriented Programming & $15 \%$ \\
Technical writing & $0 \%$ \\
& $36 \%$ \\
\hline
\end{tabular}


Table IV, V, and VI deal with general or functional categories of I.T. skills. Surveyed corporation executives and administrators considered these areas to be of greater value to a techno-business concern than the preceding specific skill. The rationale, which is compelling, states that technical skills must be combined with business intelligence over a broad range of corporate activities and integrated services. Thus, the functional areas are more in sync with the overall needs and designs of the contemporary corporation.

\begin{tabular}{|lc|}
\hline \multicolumn{2}{|c|}{ Table III. Key Information Specific Skills } \\
Health Care/Government/Not-For-Profit \\
\hline HTML & $45 \%$ \\
XML & $18 \%$ \\
ASP & $27 \%$ \\
PERL & $0 \%$ \\
Front Page/Dreamweaver & $24 \%$ \\
Java & $38 \%$ \\
C++ & $18 \%$ \\
COBOL & $15 \%$ \\
Visual Basic & $30 \%$ \\
C\# & $15 \%$ \\
NET & $15 \%$ \\
M & $38 \%$ \\
A+ & $33 \%$ \\
SQL & $27 \%$ \\
Oracle & $30 \%$ \\
Project Management & $38 \%$ \\
Programming Logic & $23 \%$ \\
Object-oriented Programming & $6 \%$ \\
Technical writing & $23 \%$ \\
\hline
\end{tabular}

\begin{tabular}{|c|c|}
\hline \multicolumn{2}{|c|}{$\begin{array}{l}\text { Table IV. Key Information Functional Area Skills } \\
\text { Large Corporate }\end{array}$} \\
\hline Web Design/Hosting & $45 \%$ \\
\hline Programming & $38 \%$ \\
\hline Tech Support & $51 \%$ \\
\hline Database & $57 \%$ \\
\hline Data Warehousing & $38 \%$ \\
\hline $\begin{array}{l}\text { Office Software } \\
\text { (Excel, Access, Word, Etc.) }\end{array}$ & $57 \%$ \\
\hline Systems Design & $30 \%$ \\
\hline Operating Systems & $23 \%$ \\
\hline Networks & $47 \%$ \\
\hline Data Center Operations & $36 \%$ \\
\hline Application Development & $64 \%$ \\
\hline
\end{tabular}

\begin{tabular}{|c|c|}
\hline \multicolumn{2}{|c|}{$\begin{array}{l}\text { Table V. Key Information Functional Area Skills } \\
\text { Small Corporate }\end{array}$} \\
\hline Web Design & $54 \%$ \\
\hline Programming & $38 \%$ \\
\hline Tech Support & $38 \%$ \\
\hline Database & $58 \%$ \\
\hline Data Warehousing & $16 \%$ \\
\hline $\begin{array}{l}\text { Office Software } \\
\text { (Excel, Access, Word, Etc.) }\end{array}$ & $71 \%$ \\
\hline Systems Design & $8 \%$ \\
\hline Operating Systems & $17 \%$ \\
\hline Networks & $42 \%$ \\
\hline Data Center Operations & $13 \%$ \\
\hline Application Development & $58 \%$ \\
\hline
\end{tabular}

\begin{tabular}{|lc|}
\hline \multicolumn{2}{|c|}{$\begin{array}{c}\text { Table VI. Key Information Functional Area Skills } \\
\text { Health Care/Government/Not-for-Profit }\end{array}$} \\
\hline Web Design & $43 \%$ \\
Programming & $39 \%$ \\
Tech Support & $50 \%$ \\
Database & $64 \%$ \\
Data Warehousing & $18 \%$ \\
Office Software & $68 \%$ \\
(Excel, Access, Word, Etc.) & \\
Systems Design & $7 \%$ \\
Operating Systems & $14 \%$ \\
Networks & $46 \%$ \\
Data Center Operations & $32 \%$ \\
Application Development & $71 \%$ \\
\hline
\end{tabular}

Survey respondents have demonstrated an accelerating trend toward the outsourcing or contracting of services formerly performed in-house. Contractors have the capability to specialize in more narrow technological areas as information needs differentiate.

The reasons to engage in outsourcing, as noted by respondents, are:

- $\quad$ Concentration on core business affairs

- $\quad$ Reduced I.T. costs

- $\quad$ Lack of relevant in-house I.T. staff

- $\quad$ Faster time to market 
- Increased flexibility

- $\quad$ Access to specialized experience

- $\quad$ Projects defined by specific time limits lend themselves to contracting

The disadvantages of outsourcing are:

- $\quad$ Loss of control of the technological base within the company

- $\quad$ Security issues may arise

- Quality of company workforce may decline

- $\quad$ Downsizing or re-direction of I.T. employee base

- Decreased morale and/or loyalty of employees

Large companies tend to outsource more often than smaller ones. Larger entities have a greater, more diverse set of functional activities to be outsourced, thus a greater number of possibilities for services exist.

Table VII displays the percentage of companies that outsource each of six functional areas that surveyed corporations considered most applicable for contracting services.

The most intriguing question that rises from the infrastructure of all contracting studies is that of the ultimate corporate downsizing movement - offshore out-

\begin{tabular}{|lc|}
\hline \multicolumn{2}{|c|}{$\begin{array}{r}\text { Table VII. Outsourcing Of I.T. Functions } \\
\text { All Corporations And Entities }\end{array}$} \\
\hline Web Design/Hosting & $26 \%$ \\
Tech Support/Help Desk & $23 \%$ \\
Database Operations & $10 \%$ \\
Networking & $32 \%$ \\
Data Center Operations & $27 \%$ \\
Application Development & $30 \%$ \\
\hline
\end{tabular}
sourcing of I.T. skills. This latent but accelerating transition threatens to change the landscape of I.T. in the United States. This researcher has met with great difficulty, not per-haps unexpected, in gathering information of a nature that corporations are reluctant to divulge, except in remote anecdotal terms. Thus, this final piece of the outsourcing puzzle remains an elusive but promising future endeavor.

Notes 